\title{
Translesion DNA synthesis in eukaryotes: A one- or two-polymerase affair
}

\author{
Satya Prakash and Louise Prakash ${ }^{1}$ \\ Sealy Center for Molecular Science, University of Texas Medical Branch, Galveston, Texas 77555-1061, USA
}

Cellular DNA is continually damaged by a plethora of extrinsic and intrinsic sources, including UV light from the sun and reactive oxygen species resulting from aerobic respiration. Although cells possess a variety of repair processes to remove DNA lesions, lesions that escape repair can block the replicational machinery, and there has been little understanding of the mechanisms by which eukaryotic cells overcome such blocks and promote the continuity of the newly replicated DNA strand. The past three years, however, have witnessed phenomenal progress in this area of research, and here we highlight the important findings and major conclusions that have emerged regarding translesion DNA synthesis (TLS) in eukaryotes.

The $R A D 6-, R A D 18$-dependent pathways for the replication of damaged DNA

Genetic studies in the yeast Saccharomyces cerevisiae have played a key role in the identification of genes involved in damage bypass and in the elucidation of their roles in this process. Inactivation of the RAD6 or RAD18 genes severely impairs both the error-free and mutagenic modes of damage bypass. Rad6, a ubiquitin-conjugating enzyme, exists in vivo in a complex with Rad18, a DNAbinding protein (Bailly et al. 1994, 1997). Genetic studies have indicated that this complex controls the bypass of UV-damaged DNA via at least three separate pathways (Torres-Ramos et al. 2002): an error-free pathway dependent on the RAD5, MMS2, and UBC13 genes; another error-free pathway dependent on the RAD 30 gene; and a third pathway that is mutagenic and dependent on the REV1, REV3, and REV7 genes. Rad5, a member of the Swi-Snf family of proteins, is a DNA-dependent ATPase but shows no DNA helicase activity (Johnson et al. 1994). Mms2 forms a complex with Ubc13, and this ubiquitin-conjugating enzyme complex affects the assembly of polyubiquitin chains linked through lysine 63 (Hofmann and Pickart 1999). Although how Rad5 pro-

${ }^{1}$ Corresponding author.

E-MAIL 1.prakash@utmb.edu; FAX (409) 747-8608.

Article and publication are at http://www.genesdev.org/cgi/doi/10.1101/ gad.1009802. motes damage bypass and how ubiquitin conjugation by the Rad6-Rad18 and Mms2-Ubs13 enzyme complexes modifies the damage bypass ability of Rad5 or of other proteins in this pathway are not known, it has been suggested that Rad5 promotes replication through UV lesions by a copy-choice type of DNA synthesis, wherein ubiquitin conjugation onto Rad5 and/or the Rad5-associated proteins, by the sequential action of the Rad6Rad18 and Mms2-Ubc13 complexes, promotes the assembly into the replication machinery of Rad5 and of proteins that function with Rad5 (Torres-Ramos et al. 2002). The RAD30-encoded DNA polymerase $\eta$ (Pol $\eta$ ) carries out error-free replication through UV-induced cyclobutane pyrimidine dimers (CPDs; Johnson et al. 1999b). The REV3- and REV7-encoded proteins together form DNA polymerase $\zeta$ (Pol $\zeta$; Nelson et al. 1996b), which promotes mutagenic bypass of DNA lesions induced by UV light and by other DNA-damaging agents. $R E V 1$ encodes a highly specialized DNA polymerase that preferentially inserts a $\mathrm{C}$ residue opposite template $\mathrm{G}$ (Nelson et al. 1996a; Haracska et al. 2002a). The RAD6, $R A D 18$ group of genes is highly conserved among eukaryotes, and counterparts of both these genes, as well as of RAD5, MMS2, UBC13, RAD30, REV1, REV3, and $R E V 7$, have been identified in humans.

\section{Lesion bypass by DNA polymerase $\eta$}

Pol $\eta$ is unique among eukaryotic DNA polymerases in its proficient ability to replicate through a cis-syn thymine-thymine (TT) dimer. Remarkably, Pol $\eta$ replicates through this lesion with the same efficiency and accuracy with which it replicates through undamaged Ts, and steady-state kinetic studies have shown that both yeast and human Poln insert an A opposite the $3^{\prime}-\mathrm{T}$ and the $5^{\prime}$-T of the TT dimer with the same efficiency and accuracy with which they insert an $\mathrm{A}$ opposite a $\mathrm{T}$ in the undamaged sequence (Johnson et al. 2000c; Washington et al. 2000).

In addition to the formation of cyclobutane dimers at two adjacent thymines, UV also induces the formation of cyclobutane dimers and (6-4) photoproducts at $5^{\prime}-\mathrm{TC}-3^{\prime}$ and $5^{\prime}-\mathrm{CC}-3^{\prime}$ sequences in the genome. The contribu- 
tion of these lesions to UV mutagenesis is supported by the fact that the $3^{\prime}$-cytosine in both these sequences is highly mutagenic, and in yeast as well as in humans, $\mathrm{C} \rightarrow \mathrm{T}$ transitions are the predominant form of UV-induced mutations (Armstrong and Kunz 1990; Brash 1997; Canella and Seidman 2000). Such mutations would arise from the insertion of an A opposite the damaged 3 '-C residue during DNA replication. In vitro bypass studies are difficult to perform with TC or CC dimers because of the instability of the $\mathrm{C}$ residue in the dimer and its subsequent deamination to $\mathrm{U}$ in vitro. Genetic studies, however, have shown that the incidence of UV-induced mutations at the $3^{\prime}-\mathrm{C}$ of $5^{\prime}-\mathrm{TC}-3^{\prime}$ and $5^{\prime}-\mathrm{CC}-3^{\prime}$ sequences rises $\sim$ fivefold in yeast cells lacking Pol $\eta$ (Yu et al. 2001). Poln thus functions in the error-free bypass of UV lesions formed at these sites as well.

Mutations in Poln in humans cause a cancer-prone syndrome, the variant form of xeroderma pigmentosum (XP-V; Johnson et al. 1999a; Masutani et al. 1999). Cells from XP-V individuals are deficient in the replication of UV-damaged DNA (Lehmann et al. 1975; Cordeiro-Stone et al. 1997), and they are hypermutable with UV light (Wang et al. 1993; Waters et al. 1993). Therefore, by promoting error-free replication of UV-damaged DNA, Pol $\eta$ prevents cancer formation.

Pol $\eta$ is also able to replicate through the oxidative lesion 7,8-dihydro-8-oxoguanine (8-oxoG; Haracska et al. $2000 \mathrm{~b})$. Although DNA polymerase $\delta$ can also replicate through this lesion, it is inefficient at it and it does so by inserting an $\mathrm{A}$, which accounts for the high incidence of $\mathrm{G} \cdot \mathrm{C}$ to $\mathrm{T} \cdot \mathrm{A}$ transversions that result from 8-oxoG bypass in both yeast and mammalian cells (Shibutani et al. 1991; Haracska et al. 2000b). Yeast Poln, however, replicates through the 8-oxoG lesion efficiently and accurately by inserting a $\mathrm{C}$ across from the lesion and by proficiently extending from the inserted C. Support for the involvement of Poln in the error-free bypass of 8-oxoG in yeast cells is provided by the observation that a synergistic rise in spontaneous $\operatorname{can}^{r}$ mutation frequencies occurs in rad30 $\Delta$ ogg1s cells that lack Pol $\eta$ as well as the Ogg1 DNA glycosylase that functions in the removal of 8-oxoG paired with $\mathrm{C}$ (Haracska et al. 2000b).

NMR studies have shown that a cis-syn TT dimer has a modest effect on DNA structure, as it unwinds DNA by $15^{\circ}$ and bends it by $\sim 9^{\circ}$; this distortion, however, does not affect the ability of two thymine bases in the dimer to maintain their parallel stacking and to base-pair with As (Ciarrocchi and Pedrini 1982; Kim et al. 1995). For the 8-oxoG lesion, the level of distortion differs depending on whether it is paired with an A or a C. In the synconformation, 8-oxoG mimics $\mathrm{T}$ and pairs with $\mathrm{A}$ via two hydrogen bonds, whereas in the anti-conformation, 8-oxoG forms a normal Watson-Crick pair with a C (Kouchakdjian et al. 1991; McAuley-Hecht et al. 1994; Lipscomb et al. 1995). The template strand, however, is significantly distorted in the 8-oxoG $\cdot \mathrm{C}$ base pair but not in the 8-oxoG - A base pair. The ability of Poln to efficiently replicate through a TT dimer, an 8-oxoG lesion, and also to replicate through other distorting DNA lesions, albeit less efficiently (Haracska et al. 2000a;
Levine et al. 2001; Minko et al. 2001), has indicated that Pol $\eta$ is rather insensitive to geometric distortions conferred on DNA by these lesions.

Replicative DNA polymerases are highly sensitive to geometric distortions in DNA, and they are unable to replicate through distorting DNA lesions. Replicative DNA polymerases are also highly intolerant of the geometric distortions imposed on DNA by the incorporation of incorrect nucleotides, and consequently, they incorporate wrong nucleotides with a very low frequency (Echols and Goodman 1991; Goodman et al. 1993). In contrast to the high fidelity of replicative polymerases, Pol $\eta$ is a low-fidelity enzyme, and it misincorporates nucleotides with a frequency of $\sim 10^{-2}$ to $10^{-3}$ (Washington et al. 1999; Johnson et al. 2000c); in a subsequent study, human Poln was shown to be highly mutagenic in an in vitro DNA synthesis reaction (Matsuda et al. 2000).

What structural and mechanistic features of Pol $\eta$ account for its damage bypass ability and low fidelity? The recently determined crystal structure of Poln and presteady-state-kinetic analyses of its nucleotide incorporation mechanism have yielded important insights into these questions.

\section{Crystal structure of Pol $\eta$}

Structures of a number of high-fidelity replicative or repair polymerases have shown that they all have a similar architecture that resembles a cupped right hand with palm, fingers, and thumb domains. In all these polymerases, the palm domain harbors the three conserved acidic residues that coordinate the binding of two divalent metal ions, and this domain also contributes to the binding of the incoming dNTP. The fingers domain makes intimate contacts with the incoming dNTP, and the thumb domain contributes to duplex DNA binding. The active site of these enzymes fits very snugly with the templating base, the incoming dNTP, and a few base pairs in the duplex DNA adjacent to the site of nucleotide incorporation. Also, and importantly, in all these polymerases, only a single unpaired template base is held in the active site, while the single-stranded template strand, including the next $5^{\prime}$ unpaired template base, is flipped out of the active site at a $90^{\circ}$ angle (Doublie et al. 1998; Kiefer et al. 1998; Li et al. 1998). All these features impose a high degree of geometric selectivity on the polymerases, which then accounts for their high fidelity and for their inability to replicate through distorting DNA lesions.

The amino acid sequence of Poln and the other members of the Y-family polymerases (Ohmori et al. 2001) is unrelated to that of the classical DNA polymerases, and is characterized by five conserved motifs, I-V. Motifs I and III in Pol $\eta$ and other Y-family polymerases contain the invariant acidic residues that are essential for polymerase function. These motifs resemble motifs A and C, respectively, of classical DNA polymerases, which are known to harbor the catalytic acidic residues (Kondratick et al. 2001). These observations had suggested a role for the conserved acidic residues present in motifs I 
and III in Poln and other Y-family polymerases in the binding of two divalent metal ions required for catalysis.

Like the classical DNA polymerases, Poln is a righthand-shaped molecule with palm, fingers, and thumb domains (Trincao et al. 2001). The palm of Poln closely resembles the palm of $\mathrm{T} 7$ and other classical DNA polymerases, and the active-site acidic residues of classical polymerases can be superimposed onto the Asp 30 residue present in motif I and the Asp 155 and Glu 156 residues present in motif III in Poln. These superpositions (Trincao et al. 2001), coupled with mutational studies of these three acidic residues in Poln (Kondratick et al. 2001), have implicated the Asp 30 and Asp 155 residues, and to a lesser extent the Glu 156 residue, in the coordination of two metal ions. The fingers and thumb domains of Poln differ strikingly from those in T7 and other classical polymerases in being very short and stubby (Fig. 1; Trincao et al. 2001). In contrast to the replicative polymerases, Pol $\eta$ harbors an additional domain, which we have termed PAD, to signify a polymerase-associated domain. The PAD domain is connected to the thumb domain by a long and flexible tether, and it resembles the palm domain in containing a mixed $\beta$-sheet and two long $\alpha$-helices (Fig. 1; Trincao et al. 2001).

Although the ternary structure of Poln bound to duplex DNA and an incoming dNTP has not yet been solved, the similarity of the palm domain of Poln to that of the classical DNA polymerases has allowed the modeling of template-primer and an incoming dNTP into the Pol $\eta$ active site. In such a modeled complex, the thumb is seen to contact the duplex portion of DNA on the minor-groove side, while the PAD contacts the duplex DNA on the major-groove side, and the long loop that connects the thumb to the PAD lies on the underside of the DNA (Fig. 1). The PAD increases the DNA binding surface of Poln by almost two times, which explains the

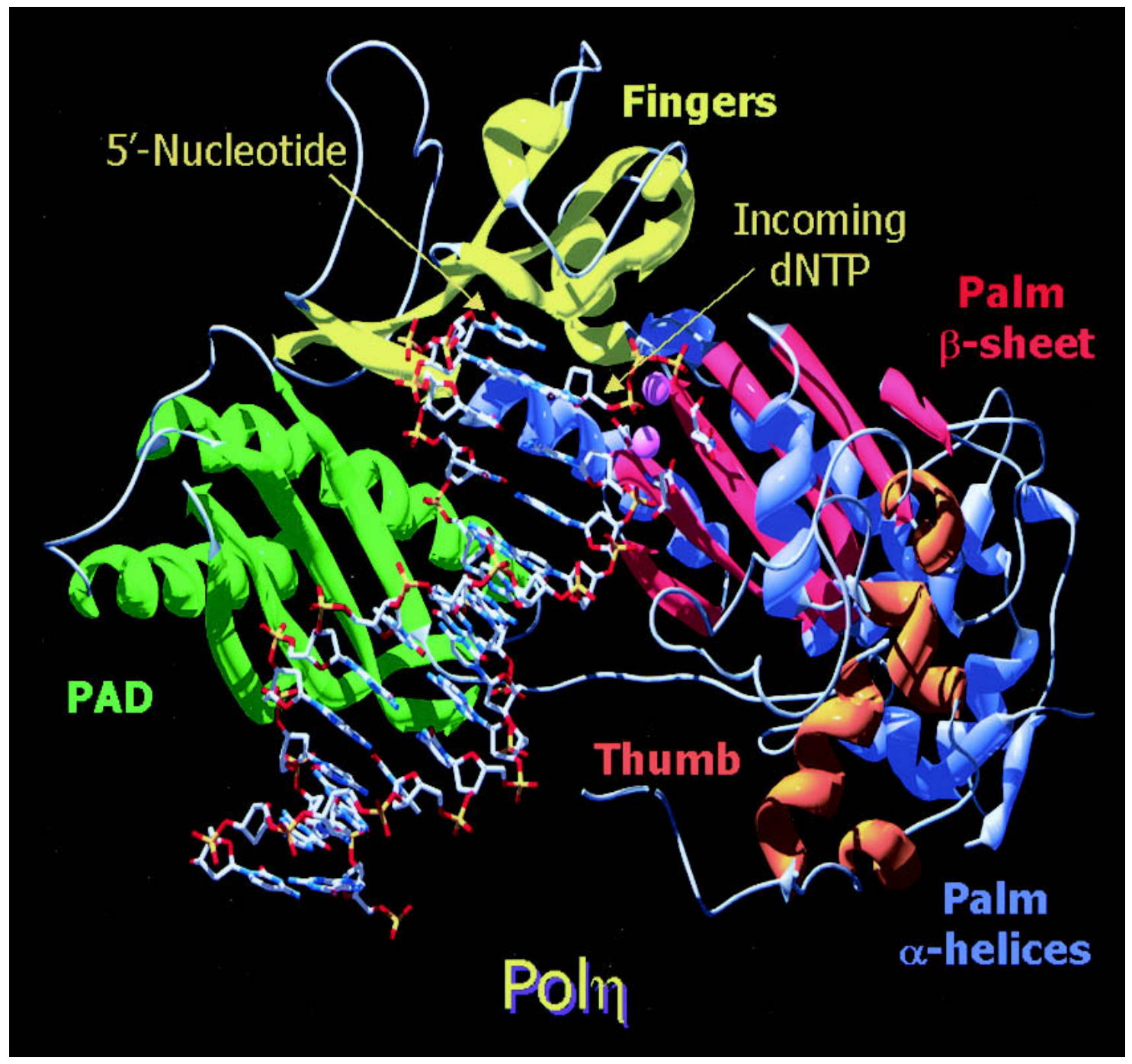

Figure 1. Structure of Pol $\eta$ with modeled DNA and an incoming dNTP. The Pol $\eta$ active site is quite open and it can accommodate two template nucleotides - the templating residue and the next $5^{\prime}$ unpaired residue. The ability of Pol $\eta$ to accommodate two template nucleotides in its active site would enable it to accommodate a cis-syn cyclobutane pyrimidine dimer, thereby permitting the efficient bypass of this DNA lesion. 
indispensability of this region for DNA synthesis (Trincao et al. 2001).

The structure of Pol $\eta$ with modeled DNA and an incoming dNTP has revealed that the Poln active site is very open, and, in fact, there is little evidence of any specific contact of the protein with the base of the incoming dNTP or with the templating base (Fig. 1; Trincao et al. 2001). Also, there is no compelling evidence of any specific minor-groove interactions of the enzyme with the base of the incoming dNTP or the templating residue or with any of the base pairs in the duplex portion of the DNA being contacted by the enzyme. X-Ray structures of several high-fidelity DNA polymerases, on the other hand, have revealed a number of minor-groove interactions involving $\mathrm{H}$-bond formation between the amino acid side-chain donors of the polymerase and the H-bond acceptor atoms (N3 of purines and $\mathrm{O} 2$ of pyrimidines) on the bases in DNA (Pelletier et al. 1994; Eom et al. 1996; Doublie et al. 1998; Kiefer et al. 1998).

The most remarkable observation to emerge from the modeling studies with Poln is the paucity of contacts with the template $5^{\prime}$-end. In contrast to the classical DNA polymerases, which can hold only one unpaired template base in their active site while the next $5^{\prime}$ unpaired template base is directed out of the active site at a $90^{\circ}$ angle, the active site of Pol $\eta$ is so unrestricted that it can accommodate two template nucleotides-the templating residue and the next $5^{\prime}$ unpaired residue (Fig. 1; Trincao et al. 2001). Because of the covalent cis-syn cyclobutane linkage of the $3^{\prime}-\mathrm{T}$ with the $5^{\prime}-\mathrm{T}$ in the TT dimer, the $5^{\prime}-\mathrm{T}$ of the dimer cannot be flipped out. Hence, the ability of Pol $\eta$ to accommodate two template bases rather than just one makes this polymerase uniquely suited for the bypass of this DNA lesion.

\section{The ternary crystal structure of Dpo4}

The crystal structure of a DinB homolog, Dbh from Sulfolobus solfataricus, has been determined in two separate studies (Silvian et al. 2001; Zhou et al. 2001), and the structure of another DinB homolog, Dpo4 from S. solfataricus, has been solved in complex with DNA and an incoming nucleotide (Ling et al. 2001). These DinB homologs resemble Pol $\eta$ in having the same basic structure with the palm, thumb, and fingers domains, and a fourth domain that is analogous to the PAD in Poln, and has been termed little finger in Dpo4. However, it should be noted that the PAD or little finger domain differs from the fingers domain in structure as well as function.

The Dpo4 ternary structure has provided important insights into the nature of interactions of this polymerase with the incoming dNTP and the DNA. Interestingly, there are no direct minor groove hydrogen bonding interactions with the base of the incoming dNTP, the templating base, or with any of the bases in the duplex portion (Ling et al. 2001). The Dpo4 ternary structure was determined in two crystal forms: type I, that has $3^{\prime}-\mathrm{TT}-5^{\prime}$ in the template and ddATP as the incoming nucleotide, and type II, with $3^{\prime}-\mathrm{GC}-5^{\prime}$ in the template and ddGTP as the incoming nucleotide. In the type I crystal, only the $3^{\prime}-\mathrm{T}$, which base pairs with the incoming A residue, is held in the active site. In the type II crystal, however, the incoming ddGTP pairs with the 5 '-C rather than forming the intended mismatch with the $3^{\prime}-\mathrm{G}$. In this structure, the $3^{\prime}-\mathrm{G}$ in the template remains unpaired, leading to a gap in the primer between the base at the $3^{\prime}$-end of the primer and the incoming nucleotide. It is not entirely clear how a phosphodiester bond could be formed across this large gap.

Based on the structure of the type II crystal, it has been suggested that by translocating two template bases in its active site, Dpo4 could promote the efficient bypass of thymine dimers (Ling et al. 2001). However, in this structure, the $5^{\prime}$ nucleotide does not stack above the template base and is displaced out of the DNA helix by $\sim 5 \AA_{\text {; }}$ this stacking is prevented due to the steric interference arising from the loops in the Dpo4 fingers domain (Fig. 2).

Dpo4 is quite inefficient at inserting nucleotides opposite the 3'-T of the TT dimer, and steady-state kinetic studies have shown that by comparison to the insertion of an A opposite an undamaged T, Dpo4 inserts an A (the nucleotide inserted most often) opposite the 3 '-T of the dimer $\sim 200$-fold less efficiently (Boudsocq et al. 2001). In contrast, Pol $\eta$ is as efficient at inserting an A opposite the $3^{\prime}-\mathrm{T}$ of the TT dimer as it inserts an A opposite an undamaged $\mathrm{T}$ and it replicates through a TT dimer with the same efficiency and accuracy as it replicates through undamaged Ts. Thus, Dpo4 is unlike Pol $\eta$ in its ability to bypass a TT dimer, and the mechanism by which Dpo4 would effect the infrequent bypass of this lesion is likely to be different from that utilized by Poln.

One possible way in which Dpo4 could insert an A opposite the $3^{\prime}-\mathrm{T}$ of the TT dimer and then extend from it is suggested from the studies that have been done with exo $^{-}$T7 DNA polymerase (Sun et al. 2000). This DNA

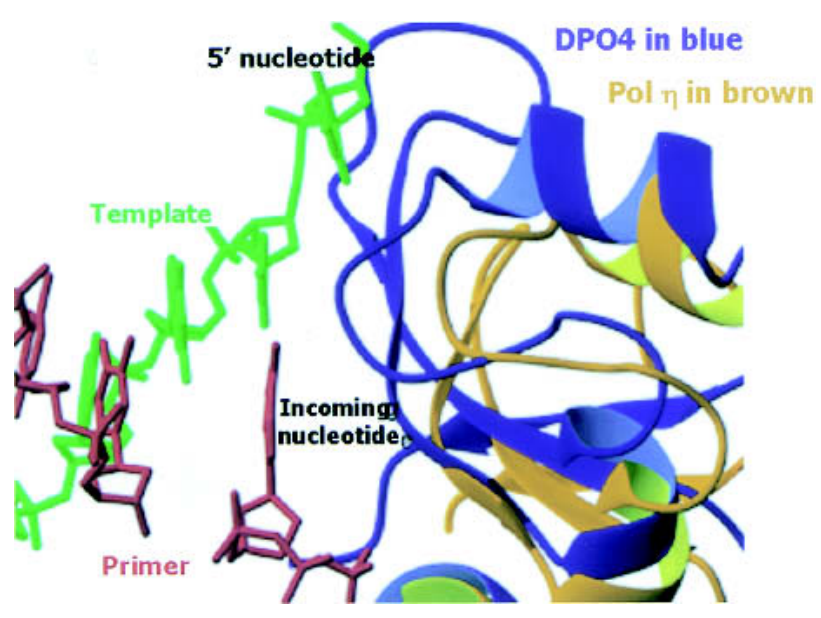

Figure 2. The Dpo4/DNA complex with Poln, based on superposition of their invariant palm domains. In the Dpo4/DNA complex, the 5 ' nucleotide is displaced out of the helix by $\sim 5 \AA$. Loops in the Dpo4 fingers domain lie above the template base. The equivalent loops in Pol $\eta$ are configured away from the template base and may allow the $5^{\prime}$ nucleotide to stack above the template base. 
polymerase can bypass a TT dimer, although quite inefficiently, and it does so by primarily inserting an A opposite the $3^{\prime}$-T of the TT dimer and then extending from it by inserting an A opposite the $5^{\prime}-\mathrm{T}$ of the TT dimer (Sun et al. 2000). However, because the exo- T7 polymerase excludes the template nucleotides present on the 5 side of the templating nucleotide from its active site, it cannot accommodate a TT dimer due to the covalent attachment of the $3^{\prime}-T$ and the $5^{\prime}-T$. As a result, both the Ts are forced out of the active site, and that results in an abasic site-like structure opposite the incoming dNTP. Preferential incorporation of an A then occurs opposite such a structure because of the tendency of most polymerases to insert an A opposite noninstructional lesions. Experimental evidence for this mechanism has been provided from studies done with pyrene nucleotide, which is selectively incorporated opposite abasic sites (Matray and Kool 1999) and thus is a useful probe for determining whether the photoproduct is outside or inside the active site. The observations that dPMP is inserted in preference to dAMP opposite the $3^{\prime}-\mathrm{T}$ of the TT dimer, and dAMP is inserted in preference to dPMP opposite the $5^{\prime}$-T of the dimer, have supported the conclusion that the nucleotide is inserted opposite the $3^{\prime}-\mathrm{T}$ of the TT dimer when the photoproduct is outside the active site, whereas nucleotide insertion opposite the $5^{\prime}-\mathrm{T}$ takes place when the dimer is inside the active site (Sun et al. 2000). Dpo4 could employ a similar mechanism for bypassing a TT dimer, in which it would incorporate an A opposite an abasic site-like structure, created from the exclusion of both the nucleotides of the TT dimer from the active site. In fact, Dpo4 preferentially incorporates an A opposite an abasic site, and it is $\sim$ threefold more efficient at this than the incorporation of an A opposite the $3^{\prime}-\mathrm{T}$ of the TT dimer (Boudsocq et al. 2001), which could reflect the limited ability of Dpo4 to exclude the dimer from its active site.

\section{An induced-fit conformational change mechanism for nucleotide incorporation in Poly}

Pre-steady-state kinetic analyses provide a powerful tool to address the catalytic mechanism of DNA polymerization, and to identify the steps at which polymerase exerts selectivity for the incorporation of correct nucleotides. Studies with the classical high-fidelity DNA polymerases, such as T7 polymerase, and Escherichia coli (Klenow) have indicated that nucleotide incorporation by DNA polymerases occurs in several discrete steps (Kuchta et al. 1987, 1988; Patel et al. 1991; Wong et al. 1991), which include the following: (1) the binding of the polymerase to the DNA template-primer; (2) the binding of the polymerase-DNA binary complex to the incoming dNTP; (3) a rate-limiting conformational change that positions the active site competent for catalysis; (4) the chemical step of phosphodiester-bond formation; (5) the return of the polymerase to the original conformational state; followed by either (6) the dissociation of the polymerase from the DNA or (7) the translocation of the polymerase to the next $3^{\prime}-\mathrm{OH}$ primer terminus. In this process, the selectivity for the correct nucleotide is exerted at steps 2 and 3 .

Although T7 DNA polymerase and E. coli Klenow discriminate between the correct and incorrect nucleotides at both the initial nucleotide-binding step and at the subsequent induced-fit conformational change step, the latter step exerts a much larger degree of selectivity than the former. At the initial nucleotide-binding step, Klenow shows only a 3.4-fold preference for the correct nucleotide over the incorrect one, whereas the discrimination between the correct and incorrect nucleotide at the induced-fit conformational change step is 5000-fold (Kuchta et al. 1987, 1988). T7 DNA polymerase is more discriminating at the initial nucleotide-binding step than Klenow, but here, too, a higher degree of discrimination is exercised at the induced-fit step (2100-fold) than that at the initial nucleotide-binding step (390-fold; Patel et al. 1991; Wong et al. 1991).

Pre-steady-state kinetic analyses with yeast Pol $\eta$ have shown that it initially binds the correct nucleotide, an A opposite template $\mathrm{T}$, with a $K_{\mathrm{D}}$ of $2.4 \mathrm{nM}$, and it binds the incorrect nucleotide, a $\mathrm{C}$ opposite template $\mathrm{T}$, with a $K_{\mathrm{D}}$ of $13 \mu \mathrm{M}$, whereas the maximum rate constants $\left(k_{\mathrm{pol}}\right)$ for the correct and incorrect nucleotide incorporations are $1.3 \mathrm{sec}^{-1}$ and $0.0087 \mathrm{sec}^{-1}$, respectively (Washington et al. 2001b). Thus, at the binding step, yeast Poln shows a selectivity of 5.4 for the correct nucleotide, and at the nucleotide incorporation step $\left(k_{\text {pol }}\right)$, it shows a selectivity of 150 -fold.

For the incorporation of correct nucleotides by the high-fidelity polymerases such as T7 and E. coli Klenow, the induced-fit conformational change step is rate-limiting, whereas the chemical step of phosphodiester-bond formation occurs rapidly and is not rate-limiting. Consequently, these polymerases use the induced-fit mechanism to discern the correctness of the geometry of the nascent base pair, and thereby they incorporate the correct nucleotide with a very high selectivity. The low fidelity of Pol $\eta$ and its increased tolerance for geometric distortions in the incipient base pair had raised the possibility that a similar rate-limiting, induced-fit mechanism might not be operational in this enzyme.

That Pol $\eta$, in fact, undergoes a rate-limiting conformational change upon nucleotide binding is supported from the following observations (Washington et al. 2001b). First, yeast Poln shows a small thio effect for the incorporation of the correct nucleotide, as the substitution of the correct incoming nucleotide dATP with dATP $\alpha$ S produces only a small reduction $(1.5$-fold $)$ in the rate of nucleotide incorporation. Because sulfur has a lower electronegativity than oxygen, the elemental effect is expected to be much greater if the chemical step of phosphodiester-bond formation is rate-limiting, and studies with phosphodiesters have indicated this effect to be 4to 11 -fold for a rate-limiting chemical step (Herschlag et al. 1991). The incorporation of the incorrect nucleotide also shows a small elemental effect (1.9), which suggests that for the incorporation of incorrect nucleotides also, the conformational change step is rate-limiting in Pol $\eta$. Second, although Poln shows no substantial elemental 
effect for the incorporation of the incorrect nucleotide, it does show a substantial elemental effect for nucleotide incorporation opposite an abasic site. Pol $\eta$ is highly inefficient at inserting nucleotides opposite an abasic site; for example, yeast Pol $\eta$ inserts an A opposite an abasic site 2000 -fold less efficiently than opposite template $\mathrm{T}$ (Haracska et al. 2001e). For the incorporation of an A opposite an abasic site, yeast Poln showed an elemental effect of 9.1, and that is consistent with the chemical step being rate-limiting. The presence of a substantial elemental effect in this case, but its absence when the correct nucleotide is being incorporated, provides further support for the premise that the chemical step is not rate-limiting for correct nucleotide incorporation. Third, pulse-chase and acid quench experiments have indicated the presence of an intermediate species in which the nucleotide is stably bound to the enzyme prior to the chemical step. From these observations, we have concluded that a rate-limiting conformational change step, which leads to stable nucleotide binding, precedes the chemical step.

Yeast Poln shows little selectivity for the correct nucleotide at the initial binding step, and the 5.4-fold selectivity at this step corresponds to a $\Delta \Delta G$ of $\sim 1.0 \mathrm{kcal} /$ mole (Washington et al. 2001b). This $\Delta \Delta G$ is similar in magnitude to the free energy differences of $\sim 0.3-1 \mathrm{kcal} /$ mole that occur between the primer-terminal correct and incorrect base pairs (Petruska et al. 1988). This suggests that the Watson-Crick H-bonding ability of the nascent base pair governs the initial nucleotide-binding step, and that geometric selection makes little contribution at this step. At the rate-limiting induced-fit step, however, Poln shows a selectivity of 150 -fold for the incorporation of the correct nucleotide over the incorrect one, and this corresponds to a $\Delta \Delta G^{\ddagger}$ of $3.0 \mathrm{kcal} / \mathrm{mole}$ (Washington et al. 2001b). Thus, at this step, Poln imposes some degree of geometric selection for discriminating between the correct and incorrect nucleotides.

\section{Lesion bypass by the sequential action of two DNA polymerases}

DNA polymerase $\eta$ promotes replication through DNA lesions such as CPDs by both inserting the nucleotide opposite the damaged template nucleotide(s) and by extending from the inserted nucleotide, and Poln performs both these tasks very efficiently. In many situations, however, replication through a lesion site requires the sequential action of two DNA polymerases, in which one inserts the nucleotide opposite the damaged template nucleotide, and the other extends from the inserted nucleotide. Hence, there are polymerases that function specifically as inserters or as extenders in the lesion bypass process.

\section{DNA polymerase $\zeta$ : an efficient extender of mispaired primer termini}

Because of the requirement of the REV3 and REV7 genes, which encode the two subunits of Pol $\zeta$, for mutagenesis induced by UV light and by other DNA-damaging agents, the prevailing notion had been that Polc was a low-fidelity enzyme with the ability to replicate through DNA lesions. This idea also gained support from the initial observation that Pol $\zeta$ could replicate through a cis-syn TT dimer, although it did so rather inefficiently (Nelson et al. 1996b). Subsequent studies carried out in our laboratory, however, have indicated that, on its own, Pol $\zeta$ is unable to carry out any significant bypass of a TT dimer. Furthermore, from steady-state kinetic analyses, we have determined that Pol $\zeta$ is highly inefficient at inserting nucleotides opposite the $3^{\prime}-\mathrm{T}$ of a TT dimer; as, for example, Pol $\zeta$ incorporates an A opposite the $3^{\prime}$-T of this lesion with an efficiency that is at least 10,000-fold lower than its ability to insert an A opposite an undamaged $T$ template residue. Pol $\zeta$ is also highly inefficient at inserting nucleotides opposite the $3^{\prime}-\mathrm{T}$ of a (6-4) TT photoproduct. The inability of $\mathrm{Pol} \zeta$ to insert nucleotides opposite these DNA lesions prompted us to examine its fidelity for nucleotide incorporation opposite undamaged DNA templates, and these studies revealed that Pol $\zeta$ has a much higher fidelity $\left(\sim 10^{-4}\right)$ than Poln (Johnson et al. 2000b). Most DNA polymerases, including Poln, extend from mismatched primer termini with approximately the same frequency with which they generate the mispair by inserting the wrong nucleotide (Mendelman et al. 1990; Goodman et al. 1993; Washington et al. 2001a). In contrast, Pol $\zeta$ is much more efficient at extending from base mispairs than it is at generating the mispairs (Johnson et al. 2000b). On undamaged DNAs, compared with its mispair formation ability $\left(f_{\text {inc }} \sim 10^{-4}\right.$ to $\left.10^{-5}\right)$, Pol $\zeta$ extends from base mispairs $\sim 100$ - to 1000 -fold better $\left(f_{\text {ext }}{ }^{0} \sim 10^{-1}\right.$ to $\left.10^{-2}\right)$. Furthermore, Pol $\zeta$ is also highly efficient at extending from mispaired termini on UV-damaged DNA. For example, compared with the extension from an A opposite an undamaged template T, Pol $\zeta$ extends from a G placed opposite an undamaged $\mathrm{T} \sim 40 \%$ as efficiently, and it also extends from a $\mathrm{G}$ opposite the $3^{\prime}-\mathrm{T}$ of a TT dimer or a (6-4) TT photoproduct equally well or even better. On the basis of such observations, the proposal was made that Pol $\zeta$ specifically acts at the extension step, and the two-polymerase mechanism for lesion bypass in eukaryotes was formulated (Johnson et al. 2000b).

\section{Two-polymerase mechanism for replication through (6-4) photoproducts}

In both yeast and humans, a (6-4) photoproduct is more mutagenic than CPDs. Experiments in $S$. cerevisiae with circular single-stranded or gapped duplex vectors containing a single cis-syn TT dimer or a (6-4) TT photoproduct have shown that whereas a cis-syn dimer is replicated very accurately with only $\sim 0.4 \%$ targeted mutations, a (6-4) TT photoproduct induces mutations in $\sim 30 \%-40 \%$ of the replicated plasmid molecules, with almost $50 \%$ of these mutations being $3^{\prime}-\mathrm{T} \rightarrow \mathrm{C}$ substitutions (Gibbs et al. 1995). In mammalian cells, also, a (6-4) TT photoproduct induces primarily targeted transitions, $\sim 50 \%$ of which are $3^{\prime}-\mathrm{T} \rightarrow \mathrm{C}$ substitutions (Kamiya et al. 1998). 
Steady-state kinetic studies with yeast and human Pol $\eta$ have shown that they both preferentially insert a G opposite the $3^{\prime}$-T of the (6-4) TT lesion, but they are unable to extend from the inserted nucleotide (Johnson et al. 2001). Relative to the insertion of an A opposite an undamaged $\mathrm{T}$ template, human and yeast Pol $\eta$ s insert a G opposite the $3^{\prime}-\mathrm{T}$ of the (6-4) TT photoproduct $\sim 50$ and 100-fold less efficiently, respectively. Subsequently, Pol $\zeta$ efficiently extends from the $G$ residue inserted opposite the $3^{\prime}-\mathrm{T}$ of the photoproduct by Poln, and Pol $\zeta$ inserts the correct nucleotide A opposite the $5^{\prime}$-T of the lesion. Consequently, a (6-4) TT photoproduct could be bypassed by the sequential action of Pol $\eta$ and Pol $\zeta$, and that would result in the $3^{\prime}-\mathrm{T} \rightarrow \mathrm{C}$ transition mutations that are observed in yeast and human cells following the replication of plasmid molecules carrying this photoproduct (Fig. 3A).

The (6-4) photoproduct is formed much more frequently at TC and CC sites than at TT sites, and at the TC site, the (6-4) lesion is formed almost as frequently as a CPD (Brash and Haseltine 1982; Brash et al. 1987; Armstrong and Kunz 1990). Similar to the insertion of a G opposite the $3^{\prime}-\mathrm{T}$ of a (6-4) TT lesion, we expect that Poln would insert a G opposite the $3^{\prime}-\mathrm{C}$ of the (6-4) TC or $\mathrm{CC}$ lesion, because the $\mathrm{O} 2$ carbonyl of the $3^{\prime}-\mathrm{C}$ in the lesion can $\mathrm{H}$-bond with a $\mathrm{G}$ in the same manner as the H-bonding of a $\mathrm{G}$ to the $3^{\prime}-\mathrm{T}$ in the (6-4) TT lesion (Lee et al. 1999). The incorporation of a G opposite the $3^{\prime}-\mathrm{C}$ of the (6-4) TC or CC lesion by Poln, followed by Pol $\zeta^{\prime} \mathrm{s}$ efficient and accurate extension by incorporating the correct nucleotide opposite the $5^{\prime}$-site of the lesion, would then promote the error-free bypass of these (6-4) photoproducts (Fig. 3B,C).

In humans, in addition to Poln, Polı could contribute to the insertion step, as it is able to insert an A or a $G$ opposite the 3'-T of the (6-4) TT photoproduct, but it does not extend from the inserted nucleotide (Johnson et al. 2000b). Presumably, Polı also inserts an A or a G opposite the 3 '-C of the (6-4) photoproducts formed at TC and CC sites. Polı would then contribute to the mutagenic as well as error-free bypass of (6-4) dipyrimidine photoproducts.

\section{Two-polymerase mechanism for replication through abasic sites}

Replication through abasic sites also entails the sequential action of two DNA polymerases in which Polל extends from the nucleotide inserted by other polymerases (Haracska et al. 2001d). As is the case for CPDs and (6-4) dipyrimidine photoproducts, Pol $\zeta$ is unable to replicate through an abasic site because of its highly inefficient ability to insert nucleotides opposite this lesion. Steadystate kinetic studies have shown that Pol $\zeta$ inserts nucleotides opposite an abasic site with the same low frequency of $\sim 10^{-4}$ as it misincorporates nucleotides opposite undamaged template residues (Haracska et al. 2001d). Pol $\zeta$, however, is very adept at extending from the nucleotide incorporated opposite an abasic site. Thus, it extends from an A, G, or C opposite the abasic site $\sim 3$-fold, $\sim 10$-fold, and $\sim 50$-fold less efficiently, respectively, than it extends from a $G$ opposite an undamaged template C (Haracska et al. 2001d).

The sequencing of genomic $\operatorname{can} 1^{r}$ mutations in yeast resulting from the replicative bypass of abasic sites has indicated that $\mathrm{A}$ is the nucleotide inserted most frequently opposite the abasic site; the nucleotides C, G, and $T$ are also incorporated, but much less often. In contrast to the requirement of only $\mathrm{Pol} \zeta$ at the extension step, however, different polymerases would function at the insertion step, with Polo primarily inserting an $\mathrm{A}$, and Poln and Rev1 inserting a G and a $\mathrm{C}$ nucleotide, respectively (Haracska et al. 2001d). Because Polo is the first polymerase to encounter the DNA lesion, it would
A.

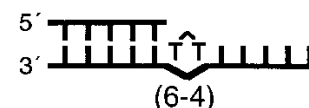

(6-4)

B.
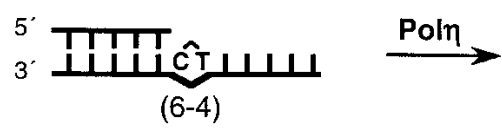

C.

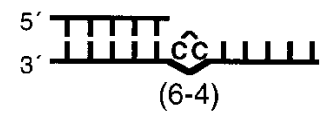

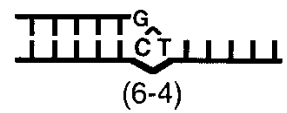

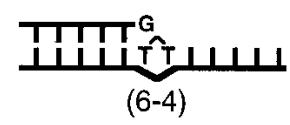

$(6-4)$

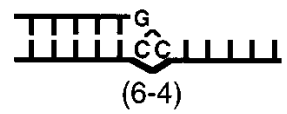

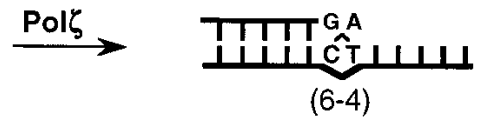


Figure 3. Replication through (6-4) photoproducts by the sequential action of Poln and Pol $\zeta$. (A) Mutagenic bypass of a (6-4) TT photoproduct. Poln inserts a G opposite the $3^{\prime}-\mathrm{T}$ of the (6-4) lesion, and Pol $\zeta$ extends by inserting an A opposite the $5^{\prime}$-T of the lesion. (B) Error-free bypass of a (6-4) TC photoproduct. Poln inserts a G opposite the $3^{\prime}-\mathrm{C}$ of the (6-4) lesion, and Pol $\zeta$ extends by inserting an A opposite the $5^{\prime}-\mathrm{T}$ of the lesion. (C) Error-free bypass of a (6-4) CC photoproduct. Poln inserts a $\mathrm{G}$ opposite the $3^{\prime}$-C of the (6-4) lesion, and Pol $\zeta$ extends by inserting a $\mathrm{G}$ opposite the $5^{\prime}-\mathrm{C}$ of the lesion. 
contribute the most to the insertion step. Although Poln is highly inefficient at inserting nucleotides opposite an abasic site, PCNA stimulates this efficiency very considerably (Haracska et al. 2001c). However, because neither the absence of Poln nor the mutational inactivation of the polymerase activity of REV1 significantly affects the mutagenesis induced by abasic sites in yeast cells, both these polymerases are dispensable for the bypass of this lesion. Because of its ability to insert nucleotides opposite an abasic site, Polı could additionally contribute to its bypass in humans (Johnson et al. 2000b).

Studies with transfection of cultured human cells with a gapped plasmid carrying an abasic site in the gap region have shown that a large majority of bypass events $(\sim 85 \%)$ occur by the insertion of an A opposite the abasic site (Avkin et al. 2002). Furthermore, the aphidicolin sensitivity of this bypass reaction has suggested the involve-

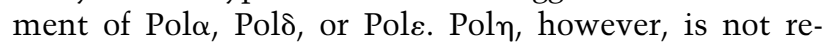
quired, because lesion bypass is not affected in XP-V cell lines (Avkin et al. 2002). The two-polymerase model developed from the genetic and biochemical studies for the bypass of abasic sites in yeast is likely to be equally applicable to humans, with the involvement of multiple polymerases, including Pol $\delta$, at the insertion step and of Pol $\zeta$ at the extension step.

Role of human DNA polymerase $\mathrm{\kappa}$ in the extension of mispaired primer termini and in lesion bypass

The human DINB1-encoded Polк, or its counterpart Pol IV from E. coli, is unable to replicate through a cis-syn TT dimer or a (6-4) TT photoproduct (Johnson et al. 2000a; Tang et al. 2000), and it has not been clear as to what extent and in what manner Polk contributes to lesion bypass. However, recent studies indicating that Polк is a proficient extender of mispaired primer termini have suggested a specific role for this polymerase at the extension step in lesion bypass (Washington et al. 2002). On undamaged DNAs, Polk misincorporates nucleotides with a frequency of $\sim 10^{-3}$ to $10^{-4}$ (Johnson et al. 2000a), whereas it extends from the mispaired primer termini with a frequency of $\sim 10^{-1}$ to $10^{-2}$ (Washington et al. 2002). Also, although Polк is unable to insert nucleotides opposite the $3^{\prime}$-T of a cis-syn TT dimer (Johnson et al. 2000a), it efficiently extends from the G nucleotide placed opposite the $3^{\prime}$-T of this lesion (Washington et al. 2002). Consequently, Polк could contribute to the mutagenic bypass of a TT dimer by extending from the $\mathrm{G}$ nucleotide inserted opposite the $3^{\prime}-\mathrm{T}$ of the dimer by another DNA polymerase (Fig. 4A). Polк could similarly contribute to the mutagenic bypass of CPDs formed at TC and CC sites, where, following the insertion by another DNA polymerase of an A opposite the $3^{\prime}-\mathrm{C}$ of a CPD formed at these sites, Polk would promote mutagenic bypass by extending from the resulting primer terminus (Fig. 4B,C). Thus, we expect Polк to act in the mutagenic bypass of CPDs formed at different dipyrimidine sites, and in this role, it would compete with Pol $\zeta$ in human cells (Fig. 4).

However, we expect Polк to make no contribution to the bypass of (6-4) photoproducts, as it is very inefficient at both the insertion of nucleotides opposite the damaged 3 '-base of this lesion, and in extending from the inserted nucleotide (Johnson et al. 2000a; Washington et

A.

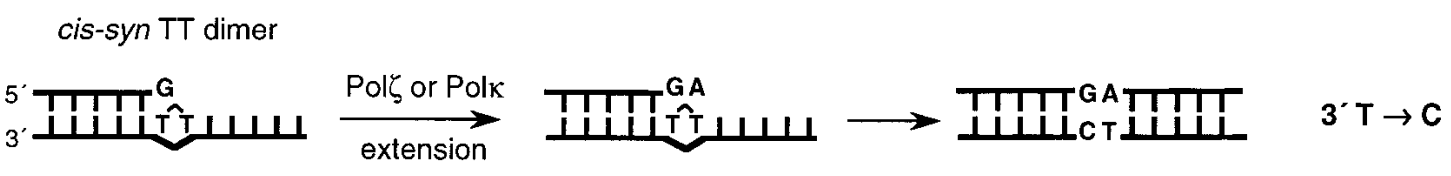

B. cis-syn TC dimer
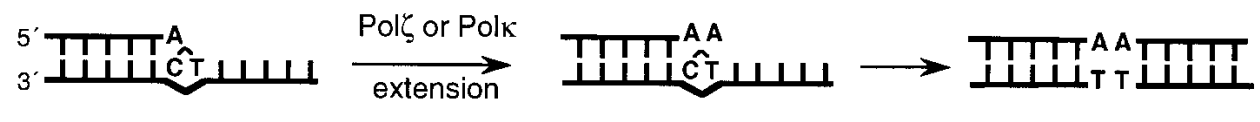

$3^{\circ} \mathrm{C} \rightarrow \mathrm{T}$

C.
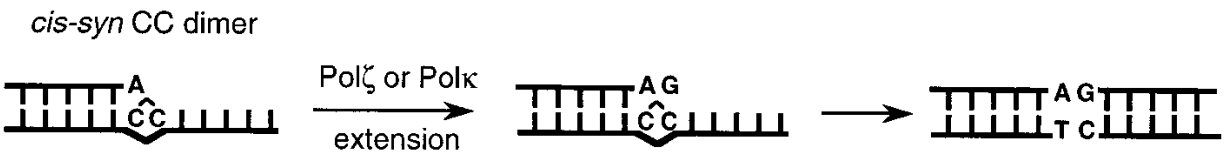

$3^{\circ} \mathrm{C} \rightarrow \mathrm{T}$

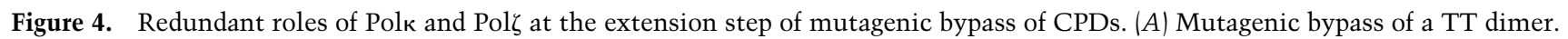

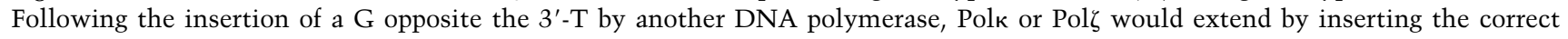
nucleotide A opposite the $5^{\prime}$ - $\mathrm{T}$. Following the next round of replication, such bypass would lead to $\mathrm{A} \cdot \mathrm{T}$ to $\mathrm{G} \cdot \mathrm{C}$ transition mutations. $(B, C)$ Mutagenic bypass of a TC $(B)$ or a CC $(C)$ dimer. Following the insertion of an A opposite the $3^{\prime}$-C, Polk or Pol $\zeta$ would extend by inserting the correct nucleotide opposite the $5^{\prime}$-residue of the dimer. Following the next round of replication, such bypass would cause $\mathrm{G} \cdot \mathrm{C}$ to $\mathrm{A} \cdot \mathrm{T}$ transition mutations. 
al. 2002). Also, Polк is highly inefficient at inserting nucleotides opposite an abasic site or in extending from the inserted nucleotide (Haracska et al. 2002b; L. Haracska, M.T. Washington, L. Prakash, and S. Prakash, unpubl.), and it is therefore unlikely to be a significant contributor to the bypass of this lesion. Although Polк appears to be much more limited in its ability to extend from primer termini on damaged DNAs than is Pol $\zeta$, future studies may reveal the specificity of Polk for extending from nucleotides opposite certain lesions not handled well by Pol $\zeta$.

\section{Contribution of DNA polymerases $\zeta$ and $\kappa$ to spontaneous mutagenesis}

Deletion of the REV3 gene in yeast decreases the rate of spontaneous base-substitution mutations by $\sim 60 \%$, and this effect extends to all types of transition and transversion mutations (Roche et al. 1994; Kunz et al. 1998). Inactivation of DNA repair genes such as $R A D 1$ and $R A D 52$ enhances the rate of spontaneous base-substitution mutations, and introduction of the rev3s mutation into these repair-deficient strains diminishes the magnitude of mutagenesis (Roche et al. 1994; Kunz et al. 1998). This response is consistent with a role of Pol $\zeta$ in promoting translesion synthesis (TLS) through DNA lesions that are formed spontaneously. Because of the involvement of NER in the removal of a variety of damaged bases and of abasic sites, the frequency of such lesions would rise in the rad1s strain, whereas the increase in mutagenesis in the rad52 $\Delta$ strain may result from the possible involvement of the RAD52 pathway in errorfree recombinational bypass of DNA lesions. The reduction in base-substitution mutations that occurs in the rev3s strain in the absence of any other DNA repair deficiency, however, may reflect not only the contribution of Pol $\zeta$ to mutagenic TLS, but also its role in the extension of mismatched primer termini that are formed during normal DNA replication. In that case, a mispair at the primer terminus would be subject to either its removal by the $3^{\prime} \rightarrow 5^{\prime}$ exonuclease of Pols, or its exten-

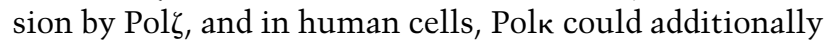
contribute to such extension (Fig. 5). Hence, in addition to their respective roles in the replication of damaged DNAs, by virtue of their proficient ability to extend from mispaired primer termini on undamaged DNAs, these polymerases could provide for a coordinated and rapid rate of fork movement during normal DNA replication.

\section{Conclusions}

A number of conclusions have emerged from the studies of eukaryotic TLS polymerases. (1) Replication through a DNA lesion can be handled by a single TLS polymerase, or it may require the sequential action of two DNA polymerases, in which one inserts the nucleotide opposite the lesion site, and the other extends from the inserted nucleotide. (2) Whether replication through a DNA lesion requires one or two TLS polymerases depends on

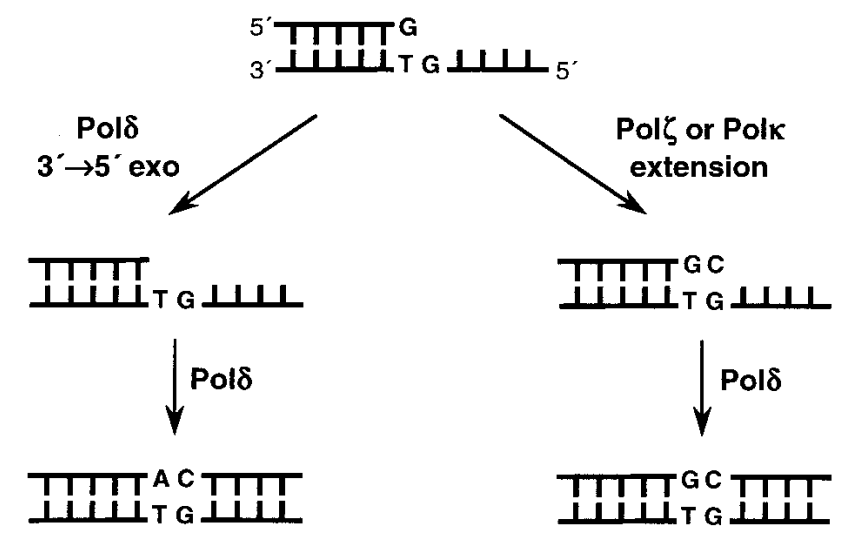

Figure 5. Alternate fates of a mismatched primer terminus. A mismatched nucleotide from the primer terminus can either be removed by the proofreading $3^{\prime} \rightarrow 5^{\prime}$ exonuclease of Pol $\delta$ (left) or

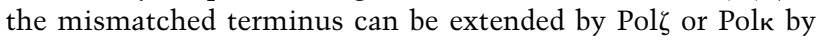
the insertion of the next correct nucleotide (right), followed by

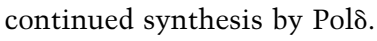

which nucleotide is inserted opposite the lesion site. For example, whereas Poln would perform error-free TLS through a CPD by inserting the correct base opposite the 3 ' damaged nucleotide and then by extending from the inserted nucleotide, if a wrong base were to be inserted opposite the 3' lesion site by Poln or by another polymerase, then Pol $\zeta$ or Polk would be required for the extension step. (3) Replication through a DNA lesion such as a (6-4) TT photoproduct, in which the $3^{\prime}-\mathrm{T}$ is highly distorted, or through an abasic site, requires two DNA polymerases, in which one acts at the insertion step and the other at the extension step. (4) Although DNA polymerases $\eta, \iota$, and $\kappa$ are all members of the same family, they differ remarkably in function. In contrast to the

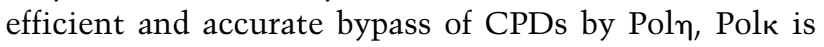
unable to insert nucleotides opposite the 3 '-nucleotide of a CPD, but it can efficiently extend from the nucleotide placed opposite this lesion site. Polı, on the other hand, shows little propensity for CPD bypass at either the insertion or the extension step. (5) DNA polymerase $\zeta$ is highly adept at extending from nucleotides placed opposite a wide variety of DNA lesions, whereas Polk seems to be much more limited in this respect. (6) The profi-

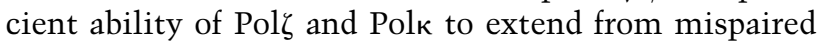
primer termini on undamaged DNAs suggests a role for both these polymerases in promoting the extension of such termini during normal DNA replication.

From the high degree of specificity in the function of TLS polymerases in lesion bypass, we surmise that they differ very considerably from one another in the manner in which they contact the template and primer nucleotides in DNA. Thus, in contrast to Pol $\eta$, whose proficiency in replicating through a CDP could be achieved by its ability to accommodate two template nucleotides in its active site, we expect the other TLS polymerases, $\kappa, \iota$, and $\zeta$, which do not bypass CPDs, to retain only the templating nucleotide in their active site. The active

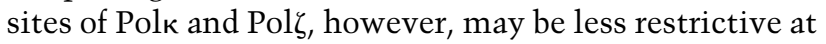


the template-primer junction for allowing the proficient extension of mispaired primer termini.

How do the TLS polymerases gain access to the replicational machinery stalled at a lesion site? Studies with

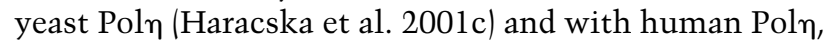
Polı, and Polк (Haracska et al. 2001a,b, 2002b) have shown that they all interact with PCNA, physically and functionally. Furthermore, mutations in yeast Poln in the conserved PCNA-binding motif, essential for this interaction, inactivate the in vivo function of Poln (Haracska et al. 2001c). These and other studies have indicated a crucial role for PCNA in the targeting of these TLS polymerases to the stalled replication fork, and future studies should reveal how the coordination of Pols with different TLS polymerases is achieved, and what factors determine which TLS polymerase will gain access to the lesion site.

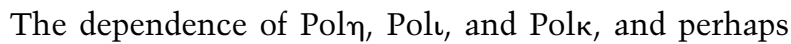
also of Pol $\zeta$, on PCNA for their function in translesion DNA synthesis suggests that they specifically promote lesion bypass during Pold-catalyzed synthesis on the leading and lagging DNA strands. The lesion bypass mechanisms, which depend on a copy-choice type of DNA synthesis or on recombination, may then be used during the Pol $\alpha$-catalyzed lagging-strand synthesis. The presence of a multiplicity of TLS polymerases in mammalian cells and in vivo and in vitro studies with vectors carrying site-specific DNA lesions (Nikolaishvili-Feinberg and Cordeiro-Stone 2000; Avkin et al. 2002) further reinforce the view that translesion DNA synthesis plays a major role in lesion bypass in mammalian cells. The embryonic lethality of $R e v 3^{-/-}$mice provides added support for the importance of translesion DNA synthesis in mammalian cells (Bemark et al. 2000; Esposito et al. 2000; Wittschieben et al. 2000).

Because translesion DNA synthesis is inherently more mutagenic than the lesion bypass mechanisms that depend on copy-choice type of DNA synthesis or on recombination, how do we account for the important role of TLS in lesion bypass in mammalian cells suggested above? One possibility is that TLS is a very efficient process, so that replication through a lesion site continues relatively unabated and the coordinated synthesis of leading and lagging strands by Pol $\delta$ is not significantly impaired. Thus, in spite of the increased mutagenicity, such a process may be inherently more advantageous than the other mechanisms where interruptions in the newly synthesized DNA strand persist for long periods, because such long-lasting discontinuities could lead to the formation of double-strand breaks in DNA, repair of which by nonhomologous recombinational means would generate gross genomic rearrangements. Evidence for such a beneficial role for TLS is provided by the observation that an increase in the incidence of chromo-

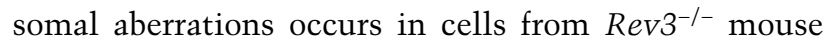
embryos (Van Sloun et al. 2002). Furthermore, the mutagenic consequences of TLS may not be as significant because it is error-free in many instances, as for example, the bypass of CPDs by Poln, and because a large proportion of the mammalian genome is noncoding, which en- sures that a vast majority of mutations will have no adverse effects on cellular physiology.

\section{Acknowledgments}

We are grateful to Robert Johnson, Todd Washington, and Lajos Haracska, members of our research group, for their contributions to the study of TLS polymerases and to the development of ideas presented here. We also wish to express our gratitude to Aneel Aggarwal and his colleagues Jose Trincao and Carlos Escalante for the solution of the crystal structure of Pol $\eta$ and for their insights into its function. We thank Aneel Aggarwal for reading the manuscript and for helpful discussions. We apologize to those whose papers could not be cited owing to space limitations. Work in our laboratory that is discussed here has been supported by grants from the National Institutes of Health.

\section{References}

Armstrong, J.D. and Kunz, B.A. 1990. Site and strand specificity of UVB mutagenesis in the SUP4-o gene of yeast. Proc. Natl. Acad. Sci. 87: 9005-9009.

Avkin, S., Adar, S., Blander, G., and Livneh, Z. 2002. Quantitative measurement of translesion replication in human cells: Evidence for bypass of abasic sites by a replicative DNA polymerase. Proc. Nat1. Acad. Sci. 99: 3764-3769.

Bailly, V., Lamb, J., Sung, P., Prakash, S., and Prakash, L. 1994. Specific complex formation between yeast RAD6 and RAD18 proteins: A potential mechanism for targeting RAD6 ubiquitin-conjugating activity to DNA damage sites. Genes \& Dev. 8: 811-820.

Bailly, V., Lauder, S., Prakash, S., and Prakash, L. 1997. Yeast DNA repair proteins Rad6 and Rad18 form a heterodimer that has ubiquitin conjugating, DNA binding, and ATP hydrolytic activities. J. Biol. Chem. 272: 23360-23365.

Bemark, M., Khamlichi, A.A., Davies, S.L., and Neuberger, M.S. 2000. Disruption of mouse polymerase $\zeta(R e v 3)$ leads to embryonic lethality and impairs blastocyst development in vitro. Curr. Biol. 10: 1213-1216.

Boudsocq, F., Iwai, S., Hanaoka, F., and Woodgate, R. 2001. Sulfolobus solfataricus P2 DNA polymerae IV (Dpo4): An archael DinB-like DNA polymerase with lesion-bypass properties akin to eukaryotic pol $\eta$. Nucleic Acids Res. 29: 46074616.

Brash, D.E. 1997. Sunlight and the onset of skin cancer. Trends Genet. 13: 410-414.

Brash, D.E. and Haseltine, W.A. 1982. UV-induced mutation hotspots occur at DNA damage hotspots. Nature 298: 189192.

Brash, D.E., Seetharam, S., Kraemer, K.H., Seidman, M.M., and Bredberg, A. 1987. Photoproduct frequency is not the major determinant of UV base substitution hot spots or cold spots in human cells. Proc. Natl. Acad. Sci. 84: 3782-3786.

Canella, K.A. and Seidman, M.M. 2000. Mutation spectra in supF: Approaches to elucidating sequence context effects. Mutat. Res. 450: 61-73.

Ciarrocchi, G. and Pedrini, A.M. 1982. Determination of pyrimidine dimer unwinding angle by measurement of DNA electrophoretic mobility. J. Mol. Biol. 155: 177-183.

Cordeiro-Stone, M., Zaritskaya, L.S., Price, L.K., and Kaufmann, W.K. 1997. Replication fork bypass of a pyrimidine dimer blocking leading strand DNA synthesis. J. Biol. Chem. 272: 13945-13954.

Doublie, S., Tabor, S., Long, A.M., Richardson, C.C., and Ellen- 
berger, T. 1998. Crystal structure of a bacteriophage T7 DNA replication complex at 2.2 A resolution. Nature 391: 251-258.

Echols, H. and Goodman, M.F. 1991. Fidelity mechanisms in DNA replication. Annu. Rev. Biochem. 60: 477-511.

Eom, S.H., Wang, J., and Steitz, T.A. 1996. Structure of Taq polymerase with DNA at the polymerase active site. Nature 382: 278-281.

Esposito, G., Godin, I., Klein, U., Yaspo, M.-L., Cumano, A., and Rajewsky, K. 2000. Disruption of the Rev31-encoded catalytic subunit of polymerase $\zeta$ in mice results in early embryonic lethality. Curr. Biol. 10: 1221-1224.

Gibbs, P.E.M., Borden, A., and Lawrence, C.W. 1995. The T-T pyrimidine (6-4) pyrimidinone UV photoproduct is much less mutagenic in yeast than in Escherichia coli. Nucleic Acids Res. 23: 1919-1922.

Goodman, M.F., Creighton, S., Bloom, L.B., and Petruska, J. 1993. Biochemical basis of DNA replication fidelity. Crit. Rev. Biochem. Mol. Biol. 28: 83-126.

Haracska, L., Prakash, S., and Prakash, L. 2000a. Replication past $O^{6}$-methylguanine by yeast and human DNA polymerase $\eta$. Mol. Cell. Biol. 20: 8001-8007.

Haracska, L., Yu, S.-L., Johnson, R.E., Prakash, L., and Prakash, S. 2000b. Efficient and accurate replication in the presence of 7,8-dihydro-8-oxoguanine by DNA polymerase $\eta$. Nat. Genet. 25: 458-461.

Haracska, L., Johnson, R.E., Unk, I., Phillips, B., Hurwitz, J., Prakash, L., and Prakash, S. 2001a. Physical and functional interactions of human DNA polymerase $\eta$ with PCNA. Mol. Cell. Biol. 21: 7199-7206.

- 2001b. Targeting of human DNA polymerase $\iota$ to the replication machinery via interaction with PCNA. Proc. Nat1. Acad. Sci. 98: 14256-14261.

Haracska, L., Kondratick, C.M., Unk, I., Prakash, S., and Prakash, L. 2001c. Interaction with PCNA is essential for yeast DNA polymerase $\eta$ function. Mol. Cell 8: 407-415.

Haracska, L., Unk, I., Johnson, R.E., Johansson, E., Burgers, P.M.J., Prakash, S., and Prakash, L. 2001d. Roles of yeast DNA polymerases $\delta$ and $\zeta$ and of Rev1 in the bypass of abasic sites. Genes \& Dev. 15: 945-954.

Haracska, L., Washington, M.T., Prakash, S., and Prakash, L. 2001 e. Inefficient bypass of an abasic site by DNA polymerase $\eta$. J. Biol. Chem. 276: 6861-6866.

Haracska, L., Prakash, S., and Prakash, L. 2002a. Yeast Rev1 protein is a G template-specific DNA polymerase. J. Biol. Chem. 277: 15546-15551.

Haracska, L., Unk, I., Johnson, R.E., Phillips, B.B., Hurwitz, J., Prakash, L., and Prakash, S. 2002b. Stimulation of DNA synthesis activity of human DNA polymerase $\kappa$ by PCNA. Mol. Cell. Biol. 22: 784-791.

Herschlag, D., Piccirilli, J.A., and Cech, T.R. 1991. Ribozymecatalyzed and nonenzymatic reactions of phosphate diesters: Rate effects upon substitution of sulfur for a nonbridging phosphoryl oxygen atom. Biochemistry 30: 4844-4854.

Hofmann, R.M. and Pickart, C.M. 1999. Noncanonical MMS2encoded ubiquitin-conjugating enzyme functions in assembly of novel polyubiquitin chains for DNA repair. Cell 96: 645-653.

Johnson, R.E., Prakash, S., and Prakash, L. 1994. Yeast DNA repair protein RAD5 that promotes instability of simple repetitive sequences is a DNA-dependent ATPase. I. Biol. Chem. 269: 28259-28262.

Johnson, R.E., Kondratick, C.M., Prakash, S., and Prakash, L. 1999a. hRAD30 mutations in the variant form of xeroderma pigmentosum. Science 285: 263-265.

Johnson, R.E., Prakash, S., and Prakash, L. 1999b. Efficient by- pass of a thymine-thymine dimer by yeast DNA polymerase, Poln. Science 283: 1001-1004.

- 2000a. The human DINB1 gene encodes the DNA poly-

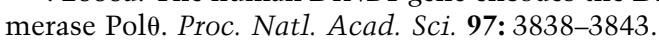

Johnson, R.E., Washington, M.T., Haracska, L., Prakash, S., and Prakash, L. 2000b. Eukaryotic polymerases $\iota$ and $\zeta$ act sequentially to bypass DNA lesions. Nature 406: 1015-1019.

Johnson, R.E., Washington, M.T., Prakash, S., and Prakash, L. 2000c. Fidelity of human DNA polymerase $\eta$. J. Biol. Chem. 275: 7447-7450.

Johnson, R.E., Haracska, L., Prakash, S., and Prakash, L. 2001. Role of DNA polymerase $\eta$ in the bypass of a (6-4) TT photoproduct. Mol. Cell. Biol. 21: 3558-3563.

Kamiya, H., Iwai, S., and Kasai, H. 1998. The (6-4) photoproduct of thymine-thymine induces targeted substitution mutations in mammalian cells. Nucleic Acids Res. 26: 26112617.

Kiefer, J.R., Mao, C., Braman, J.C., and Beese, L.S. 1998. Visualizing DNA replication in a catalytically active Bacillus DNA polymerase crystal. Nature 391: 304-307.

Kim, J.-K., Patel, D., and Choi, B.-S. 1995. Contrasting structural impacts induced by cis-syn cyclobutane dimer and (64) adduct in DNA duplex decamers: Implication in mutagenesis and repair activity. Photochem. Photobiol. 62: 44-50.

Kondratick, C.M., Washington, M.T., Prakash, S., and Prakash, L. 2001. Acidic residues critical for the activity and biological function of yeast DNA polymerase $\eta$. Mol. Cell. Biol. 21: 2018-2025.

Kouchakdjian, M., Bodepudi, V., Shibutani, S., Eisenberg, M., Johnson, F., Grollman, A.P., and Patel, D.J. 1991. NMR structural studies of the ionizing radiation adduct 7-hydro8-oxodeoxyguanosine (-8-oxo-7 H-dG) opposite deoxyadenosine in a DNA duplex. 8-oxo-7H-dG(syn) $\cdot \mathrm{dA}($ anti) alignment at lesion site. Biochemistry 30: 1403-1412.

Kuchta, R.D., Mizrahi, V., Benkovic, P.A., Johnson, K.A., and Benkovic, S.J. 1987. Kinetic mechanism of DNA polymerase I (Klenow). Biochemistry 26: 8410-8417.

Kuchta, R.D., Benkovic, P., and Benkovic, S.J. 1988. Kinetic mechanism whereby DNA polymerase I (Klenow) replicates DNA with high fidelity. Biochemistry 27: 6716-6725.

Kunz, B.A., Ramachandran, K., and Vonarx, E.J. 1998. DNA sequence analysis of spontaneous mutagenesis in Saccharomyces cerevisiae. Genetics 148: 1491-1505.

Lee, J.-H., Hwang, G.-S., and Choi, B.-S.. 1999. Solution structure of a DNA decamer duplex containing the stable $3^{\prime} \mathrm{T} \cdot \mathrm{G}$ base pair of the pyrimidine(6-4)pyrimidone photoproduct [(6-4) adduct]: Implications for the highly specific $3^{\prime} \mathrm{T} \rightarrow \mathrm{C}$ transition of the (6-4) adduct. Proc. Natl. Acad. Sci. 96: 6632-6636.

Lehmann, A.R., Kirk-Bell, S., Arlett, C.F., Paterson, M.C., Lohman, P.H.M., de Weerd-Kastelein, E.A., and Bootsma, D. 1975. Xeroderma pigmentosum cells with normal levels of excision repair have a defect in DNA synthesis after UVirradiation. Proc. Natl. Acad. Sci. 72: 219-223.

Levine, R.L., Miller, H., Grollman, A., Ohashi, E., Ohmori, H., Masutani, C., Hanaoka, F., and Moriya, M. 2001. Translesion DNA synthesis catalyzed by human Pol $\eta$ and Pol $\kappa$ across 1, $N^{6}$-ethenodeoxyadenosine. I. Biol. Chem. 276: 18717-18721.

Li, Y., Korolev, S., and Waksman, G. 1998. Crystal structures of open and closed forms of binary and ternary complexes of the large fragment of Thermus aquaticus DNA polymerase I: Structural basis for nucleotide incorporation. EMBO $J$. 17: 7514-7525.

Ling, H., Boudsocq, F., Woodgate, R., and Yang, W. 2001. Crystal structure of a Y-family DNA polymerase in action: A 
mechanism for error-prone and lesion-bypass replication. Cell 107: 91-102.

Lipscomb, L.A., Peek, M.E., Morningstar, M.L., Verghis, S.M., Miller, E.M., Rich, A., Essignman, J.M., and Williams, L.D. 1995. X-Ray structure of a DNA decamer containing 7,8dihydro-8-oxoguanine. Proc. Natl. Acad. Sci. 92: 719-723.

Masutani, C., Kusumoto, R., Yamada, A., Dohmae, N., Yokoi, M. ,Yuasa, M., Araki, M., Iwai, S., Takio, K., and Hanaoka, F. 1999. The $X P V$ (xeroderma pigmentosum variant) gene encodes human DNA polymerase $\eta$. Nature 399: 700-704.

Matray, T.J. and Kool, E.T. 1999. A specific partner for abasic damage in DNA. Nature 399: 704-708.

Matsuda, T., Bebenek, K., Masutani, C., Hanaoka, F., and Kunkel, T.A. 2000. Low fidelity DNA synthesis by human DNA polymerase $\eta$. Nature 404: 1011-1013.

McAuley-Hecht, K.E., Leonard, G.A., Gibson, N.J., Thomson, J.B., Watson, W.P., Hunter, W.N., and Brown, T. 1994. Crystal structure of a DNA duplex containing 8-hydroxydeoxyguanine-adenine base pairs. Biochemistry 33: 10266-10270.

Mendelman, L.V., Petruska, J., and Goodman, M.F. 1990. Base mispair extension kinetics. Comparison of DNA polymerase $\alpha$ and reverse transcriptase. J. Biol. Chem. 265: 2338-2346.

Minko, I.G., Washington, M.T., Prakash, L., Prakash, S., and Lloyd, R.S. 2001. Translesion DNA synthesis by yeast DNA polymerase $\eta$ on templates containing $N^{2}$-guanine adducts of 1,3-butadiene metabolites. J. Biol. Chem. 276: 25172522.

Nelson, J.R., Lawrence, C.W., and Hinkle, D.C. 1996a. Deoxycytidyl transferase activity of yeast REV1 protein. Nature 382: 729-731.

- 1996b. Thymine-thymine dimer bypass by yeast DNA polymerase $\zeta$. Science 272: 1646-1649.

Nikolaishvili-Feinberg, N. and Cordeiro-Stone, M. 2000. Discrimination between translesion synthesis and template switching during bypass replication of thymine dimers in duplex DNA. J. Biol. Chem. 275: 30943-30950.

Ohmori, H., Friedberg, E.C., Fuchs, R.P.P., Goodman, M.F., Hanaoka, F., Hinkle, D., Kunkel, T.A., Lawrence, C.W., Livneh, Z., Nohmi, T., et al. 2001. The Y-family of DNA polymerases. Mol. Cell 8: 7-8.

Patel, S.S., Wong, I., and Johnson, K.A. 1991. Pre-steady state kinetic analysis of processive DNA replication including complete characterization of an exonuclease-deficient mutant. Biochemistry 30: 511-525.

Pelletier, H., Sawaya, M.R., Kumar, A., Wilson, S.H., and Kraut, J. 1994. Structure of ternary complexes of rat DNA polymerase $\beta$, a DNA template-primer, and ddCTP. Science 264: 1891-1903.

Petruska, J., Goodman, M.F., Boosalis, M.S., Sowers, L.C., Cheong, C., and Tinoco, I. 1988. Comparison between DNA melting themodynamics and DNA polymerase fidelity. Proc. Natl. Acad. Sci. 85: 6252-6256.

Roche, H., Gietz, R.D., and Kunz, B.A. 1994. Specificity of the yeast rev3 $\Delta$ antimutator and REV3 dependency of the mutator resulting from a defect $(\mathrm{rad} 1 \Delta)$ in nucleotide excision repair. Genetics 137: 637-646.

Shibutani, S., Takeshita, M., and Grollman, A.P. 1991. Insertion of specific bases during DNA synthesis past the oxidationdamaged base 8-oxodG. Nature 349: 431-434.

Silvian, L.F., Toth, E.A., Pham, P., Goodman, M.F., and Ellenberger, T. 2001. Crystal structure of a DinB family errorprone DNA polymerase from Sulfolobus solfataricus. $\mathrm{Na}$ ture Structural Biology 8: 984-989.

Sun, L., Wang, M., Kool, E.T., and Taylor, J.-S. 2000. Pyrene nucleotide as a mechanistic probe: Evidence for a transient abasic site-like intermediate in the bypass of dipyrimidine photoproducts by T7 DNA polymerase. Biochemistry 39: $14603-14610$.

Tang, M., Pham, P., Shen, X., Taylor, J.-S., O'Donnell, M., Woodgate, R., and Goodman, M.F. 2000. Roles of E. coli DNA polymerase IV and V in lesion-targeted and untargeted SOS mutagenesis. Nature 404: 1014-1018.

Torres-Ramos, C., Prakash, S., and Prakash, L. 2002. Requirement of RAD5 and MMS2 for post replication repair of UVdamaged DNA in Saccharomyces cerevisiae. Mol. Cell. Biol. 22: 2419-2426.

Trincao, J., Johnson, R.E., Escalante, C.R., Prakash, S., Prakash, L., and Aggarwal, A.K. 2001. Structure of the catalytic core of $S$. cerevisiae DNA polymerase $\eta$ : Implications for translesion DNA synthesis. Mol. Cell 8: 417-426.

Van Sloun, P.P.H., Varlet, I., Sonneveld, E., Boei, J.J.W.A., Romeijn, R.J., Eeken, J.C.J., and De Wind, N. 2002. Involvement of mouse Rev3 in tolerance of endogenous and exogenous DNA damage. Mol. Cell. Biol. 22: 2159-2169.

Wang, Y.-C., Maher, V.M., Mitchell, D.L., and McCormick, J.J. 1993. Evidence from mutation spectra that the UV hypermutability of xeroderma pigmentosum variant cells reflects abnormal, error-prone replication on a template containing photoproducts. Mol. Cell. Biol. 13: 4276-4283.

Washington, M.T., Johnson, R.E., Prakash, S., and Prakash, L. 1999. Fidelity and processivity of Saccharomyces cerevisiae DNA polymerase $\eta$. J. Biol. Chem. 274: 36835-36838.

- 2000. Accuracy of thymine-thymine dimer bypass by Saccharomyces cerevisiae DNA polymerase $\eta$. Proc. Nat1. Acad. Sci. 97: 3094-3099.

. 2001a. Mismatch extension ability of yeast and human DNA polymerase $\eta$. J. Biol. Chem. 276: 2263-2266.

Washington, M.T., Prakash, L., and Prakash, S. 2001b. Yeast DNA polymerase $\eta$ utilizes an induced fit mechanism of nucleotide incorporation. Cell 107: 917-927.

Washington, M.T., Johnson, R.E., Prakash, L., and Prakash, S. 2002. Humn DINB1-encoded DNA polymerase $\mathrm{\kappa}$ is a promiscuous extender of mispaired primer termini. Proc. Nat1. Acad. Sci. 99: 1910-1914.

Waters, H.L., Seetharam, S., Seidman, M.M., and Kraemer, K.H. 1993. Ultraviolet hypermutability of a shuttle vector propagated in xeroderma pigmentosum variant cells. I. Invest. Derm. 101: 744-748.

Wittschieben, J., Shivji, M.K.K., Lalani, E., Jacobs, M.S., Marini, F., Gearhart, P.M., Rosewell, I., Stamp, G., and Wood, R.D. 2000. Disruption of the developmentally regulated Rev31 gene causes embryonic lethality. Curr. Biol. 10: 1217-1220.

Wong, I., Patel, S.S., and Johnson, K.A. 1991. An induced-fit kinetic mechanism for DNA replication fidelity: Direct measurement by single-turnover kinetics. Biochemistry 30: 526-537.

Yu, S.-L., Johnson, R.E., Prakash, S., and Prakash, L. 2001. Requirement of DNA polymerase $\eta$ for error-free bypass of UVinduced CC and TC photoproducts. Mol. Cell. Biol. 21: 185188.

Zhou, B.-L., Pata, J.D., and Steitz, T.A. 2001. Crystal structure of a DinB lesion bypass DNA polymerase catalytic fragment reveals a classic polymerase catalytic domain. Mol. Cell 8: $427-437$. 


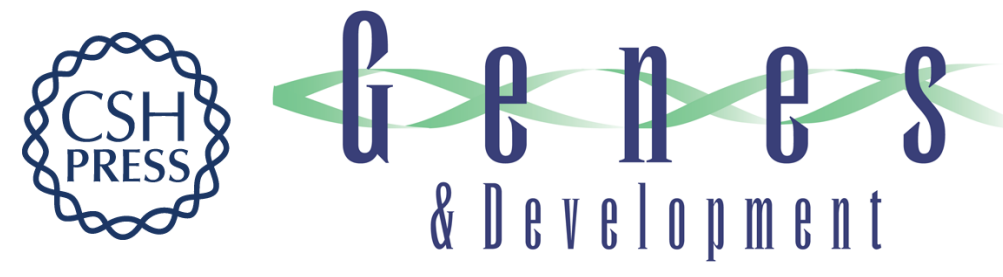

\section{Translesion DNA synthesis in eukaryotes: A one- or two-polymerase affair}

Satya Prakash and Louise Prakash

Genes Dev. 2002, 16:

Access the most recent version at doi:10.1101/gad.1009802

References This article cites 82 articles, 41 of which can be accessed free at: http://genesdev.cshlp.org/content/16/15/1872.full.html\#ref-list-1

License

Email Alerting Receive free email alerts when new articles cite this article - sign up in the box at the top Service right corner of the article or click here.

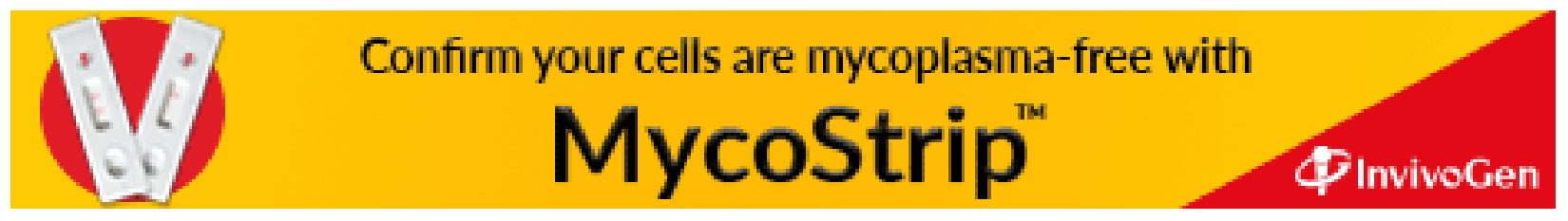

